\title{
A SIGNIFICANT QUALITY STANDARD IN TERMS OF PERCENT ROOT COLONIZATION FOR EFFECTIVITY OF THE ARBUSCULAR MYCORRHIZAL (AM) INOCULUM
}

\section{SARANYA KUPPUSAMY1* AND KUMUTHA K. ${ }^{2}$}

Dept. of Agricultural Microbiology, Tamil Nadu Agricultural University, Coimbatore- 641 003, TN, India.

*Corresponding Author: Email- 'saran.miles2go@gmail.com, 2kkumuthatnau@yahoo.com

Received: December 03, 2011; Accepted: March 01, 2012

\begin{abstract}
With a prime motive to confirm the high quality of Arbuscular Mycorrhizal (AM) inoculum that is widely used as an important biofertilizer, an effort was taken to standardize the per cent colonized root bits that have to be present in an AM inoculum. Initial analysis on AM colonization for the effectivity of the AM inoculum revealed that 80 per cent to 100 per cent root colonization enhanced the growth performance of the host plant with better mycorrhizal responses which were assessed in terms of per cent root colonization and viable spore count of Glomus intraradices when the substrate vermiculite was amended with 10 per cent soil compared to vermiculite alone at 60 days. Thus, presence of $>80$ per cent colonized root bits in AM inoculum was standardized as one of the quality control parameter of AM inoculum which can be adopted to certify a high quality AM product commercially .
\end{abstract}

Key words - Root colonization, quality, AM fungi and inoculum

Citation: Saranya Kuppusamy and Kumutha K. (2012) A Significant Quality Standard in Terms of Percent Root Colonization for Effectivity of the Arbuscular Mycorrhizal (AM) Inoculum. International Journal of Microbiology Research, ISSN: 0975-5276 \& E-ISSN:0975-9174, Volume 4, Issue 2, pp.-168-172.

Copyright: Copyright@2012 Saranya Kuppusamy and Kumutha K. This is an open-access article distributed under the terms of the Creative Commons Attribution License, which permits unrestricted use, distribution, and reproduction in any medium, provided the original author and source are credited.

\section{Introduction}

The growing number of new, small to medium sized companies (SME's) around the world producing inocula of mycorrhizal fungi has increased in the last decades (Feldmann and Schneider, 2009). This means that these producers see market opportunities for application of mycorrhizal fungi. Many companies have therefore spunout of the academic and research world into the business world. Many end users find that the promises made about the product and the results seen are often world apart. This has led to sweeping positive and negative generalizations about the efficacy of mycorrhizal products currently available. Still, there are major problems in bringing high quality and fit for purpose AM fungal products to target markets. Because AM fungi are obligate symbionts, the production of AM fungal inocula of the best quality is still challenging (Douds et al., 2010).

Companies have taken different approaches in their market approach, ranging from products with single AM fungi for specific market to mixed products for general markets. Whatever may be the approach, the quality of AM inoculum produced by different companies is not based on quality regulations. Therefore, more accurate methods are required to ensure a high quality and consistent AM inoculant (Feldmann et al., 2010). Hence, the present investigation was undertaken to develop quality standards for AM inoculant in terms of the colonized root bits that act as a significant component of $A M$ inoculum.

\section{Materials and Methods}

To standardize the percent root colonization of AM in the inoculum for enhanced effectivity, this study was conducted.

\footnotetext{
Assessment of AM colonization in the roots of host plant The root samples were collected from the maize plant that was raised for the development of the 'mother' inoculum. The roots were processed and AM colonization was estimated by adopting the procedure described by Phillips and Hayman (1970). Based on the per cent root colonization, the inoculum with different AM root colonization (as given below) was prepared and used for this study.
} 


\section{Treatment Details \\ Treatments}

$\mathrm{T}_{1}$ - Uninoculated control

$\mathrm{T}_{2}-60 \%$ colonized root bits

$\mathrm{T}_{3}-80 \%$ colonized root bits

$\mathrm{T}_{4}-100 \%$ colonized root bits

Levels

$$
\begin{aligned}
& S_{1} \text { - Vermiculite alone } \\
& S_{2}-\text { Vermiculite }+10 \% \text { sterile soil }
\end{aligned}
$$

\section{Substrate}

Raw vermiculite (Grade IV) obtained from Tamil Nadu Minerals, Chennai was sterilized and used in this experiment, with and without the amendment of $10 \%$ sterile field soil collected from Eastern Block, TNAU Coimbatore. The substrate was sterilized at $15 \mathrm{lbs}$ pressure for 30 minutes and was used for this experiment. The substrates were filled in black pots $(15 \times 15 \mathrm{~cm})$ about $1 \mathrm{~kg} \mathrm{pot}^{-1}$.

\section{Preparation of AM inoculum}

About $5 \mathrm{~g}$ of the root bits colonized by Glomus intraradices with different levels of colonization as per the respective treatment was applied as inoculum, approximately $2.5 \mathrm{~cm}$ below the sterile pot mix for each treatment. The rate of inoculum was $5 \mathrm{~g} \mathrm{pot}^{-1}$ filled with $1 \mathrm{~kg}$ of substrate.

\section{AM multiplication and sampling}

Surface sterilized maize (variety PEHM 5) seeds were sown. Five plants were retained in each pot. The pots were watered regularly. Once in 15 days each pot was given with $20 \mathrm{ml}$ of $2 x$ Hoagland solution minus phosphate (Hoagland and Arnon, 1950). Plant samples were collected from each treatment on 45 and 60 days after sowing.

\section{Experimental design}

The pots were arranged in completely randomized block design with five replications per treatment.

\section{Observations}

At each sampling, root volume and plant dry weight of host plants were recorded. In addition, root colonization, total root length colonization by AM and viable AM spore count were estimated.

\section{Plant dry weight}

The uprooted plants were sun dried for one day and then dried in hot air oven at 60 to $70^{\circ} \mathrm{C}$ for three consecutive days till the constant dry weight was obtained. The dry weights were recorded and expressed in g plant $^{-1}$.

\section{Root volume}

Volume of the root samples were determined by volume displacement analysis (Burdette, 1979). Initially, a graduated cylinder that would be large enough to fit the root being measured was selected. After filling the graduated cylinder with water to a satisfactory level, the volume of water alone was recorded. After that, the root was carefully placed in the graduated cylinder and the volume of water and root was recorded. In order to calculate the volume of the irregularly shaped root, the volume of the water alone was subtracted from the volume of the water and root and the values were expressed in $\mathrm{cm}^{3}$ plant-1.

\section{AM fungal colonization in roots of the host plant}

Roots of maize uprooted on $45^{\text {th }}$ and $60^{\text {th }}$ days after sowing were assessed for AM fungal colonization by following root clearing and staining technique developed by Phillips and Hayman (1970).

The uprooted roots were thoroughly washed in tap water to remove any soil or vermiculite particles. The roots were then cut into small bits of about $1 \mathrm{~cm}$ long and immersed in $10 \%$ potassium hydroxide solution. This was autoclaved with $5 \mathrm{lbs}$ pressure for 10 minutes, and washed with water till the brown colour disappeared. Then the roots were immersed in $2 \%$ hydrochloric acid for about 5 to 10 minutes, and the acid was decanted. Tryphan blue $0.05 \%$ prepared with lactoglycerol was added $(45 \mathrm{ml}$ of lactic acid $+45 \mathrm{ml}$ of glycerol $+10 \mathrm{ml}$ of distilled water was mixed and added with $0.05 \mathrm{~g}$ Tryphan blue) after fixation with $2 \% \mathrm{HCl}$. After staining, the root bits were kept as such overnight. Observation of the stained root bits for fungal infection under Olympus CX 40 microscope was carried out after destaining the stained roots with lactoglycerol (1:1) or glycerol $50 \%$ in order to remove the excess stain. Per cent of AM fungal colonization was calculated using the formula,

$$
\text { Per cent AM colonization }=\frac{\text { Number of root bits colonized }}{\text { Total number of root bits examined }} \times 100
$$

\section{Total Root Length colonization (TRLC) in Maize}

Total root length colonized by hyphae, arbuscules and vesicles was estimated by grid line intersection method (McGonigle et al., 1990). Maize roots were stained using tryphan blue stain. For each subsample two to four slides were used. However all the slides for a subsample were treated as a single unit, and not as subsamples. A graticule with a cross hair was prepared and attached in the eye piece. The roots were aligned parallel to the long axis of the slides and observed at magnification of $200 x$.

The alignment of the roots parallel to the horizontal line of the cross hairs was adjusted to right angle to the long axis of the root by the rotation of the vertical crosshairs. Where the centre of the crosshairs entered a root through an end rather than a side, i.e. the point of exit from the root through its side was taken as the point of intersection. Roots too wide to fit into the field of view at 40x magnification were examined in two or more width portions. The plane of focus was completely moved through the root to examine each intersection and a note of whether the vertical crosshairs actually cut any arbuscules, coils, vesicles and hyphae was made. The number of intersections was counted in the following categories viz., arbuscules, vesicles, coils or hyphae. When the vertical crosshairs cut one or more arbuscules or vesicles, the appropriate category was incremented by one and a similar increment was given for intersections where hyphae only were crossed. The arbuscular colonization (AC) and other categories (hyphae, coils, vesicles) colonization were calculated by dividing the count for the arbuscules and categories respectively by the total number of intersections examined.

Finally the total root length colonization (TRLC) was calculated using the formula as given below:

$$
T R L C=A C+V C+H C+C C
$$

where,

$$
\begin{aligned}
& \text { AC- Arbuscular colonization } \\
& \text { VC - Vesicular colonization } \\
& \text { HC - Hyphal colonization } \\
& \text { CC- Coil colonization }
\end{aligned}
$$




\section{Quantification of the AM spore density}

AM fungal spores were extracted from the rhizosphere substrate of maize by using the Wet sieving and Decantation Technique. Total number of viable spores were counted by following the procedure as follows.

Sievings from each sieve $(180 \mu$ and $106 \mu)$ collected separately in to small beakers was transferred again into the fine sieve $(45$ $\mu$ ). The sievings from fine sieve was collected using a fine get of water into a griddled filter paper funnel so as to remove the excess water. The filter paper was griddled at one half of the sheet and it was folded in such a way that the marked portion was the receiving surface during filtration. After the filtration the filter paper was removed gently and spreaded on a bigger size Petriplate with spores \& other debris and observed under stereozoom microscope. Presence of viable spores were counted by moving the Petriplate and the total number of viable spores were calculated corresponding to the weight of soil taken for analysis and the result was expressed as number $100 \mathrm{~g}^{-1}$ of the sample sieved.

\section{Statistical analysis}

The data obtained were analyzed by a three and two factorial analysis of variance $(p=0.05)$ wherever possible, with days after sowing, treatments and substrates as experimental factors using AGRES software, with mean separation by Least significant difference (LSD) as per the methods detailed by the Panse and Sukhatme (1978). The analysis for microbial population count was based on the log and arcsine transformed values.

\section{Result}

An attempt was made to standardize the AM colonization in the inoculum in order to ensure the effectivity. The AM inoculum was prepared using various levels of colonized root bits and was inoculated in two different substrates and the response in maize (cultivar PEHM 5) was studied upto 60 days after sowing. The results of this experiment are presented below.

\section{Root volume and total dry weight of Maize}

Results presented in Table 1, gives a vivid idea that AM inoculum containing various levels of colonization significantly influenced the root volume and total dry weight of maize that was used as the host plant. Both substrates recorded a notable significant increase in the plant parameters that were studied. At each level of AM colonization in the inoculum, especially at higher colonization level of $100 \%$, the increase in the root volume and total dry weight was observed and it ranges from $2.5 \mathrm{~cm}^{3}$ to $2.8 \mathrm{~cm}^{3}$ and 5.9 to $8.0 \mathrm{~g}$ respectively when vermiculite alone was used as the substrate on 60 days after plant growth. The root volume was further increased to the tune of 52.9 to 76.4 per cent when vermiculite $+10 \%$ soil was used as the substrate material at 60 days after plant growth. Similar trend was observed in total dry weight of maize where the dry weight was enhanced to the tune of 113.3 to 170.0 per cent.

The interaction effect between treatments and days was significant in case of root volume. Whereas in case of dry weight treatments $x$ days and treatments $x$ substrates were observed significant.

\section{Root colonization of Maize by AM fungi}

The results presented in Table 2 indicated the influence of AM inoculum having various levels of root colonization on the infection of maize at all the days of crop growth. AM inoculation recorded root colonization of 56 to 85 per cent at 45 days after sowing when vermiculite was used for inoculum development. When $10 \%$ sterile field soil amended with vermiculite was used as the base material the root colonization of maize by AM fungi was still enhanced upto 90 per cent on 45 days.

At 60 days, the AM inoculation of various levels of root colonization in vermiculite alone or vermiculite amended with sterile soil reached its peak of 96 and 98 per cent respectively at higher level of root colonization (100\% colonized root bits) in AM inoculum followed by $80 \%$ colonized root bits (Plate 1). The interaction effect was significant except the one's between days and substrates followed by treatments, days and substrates.
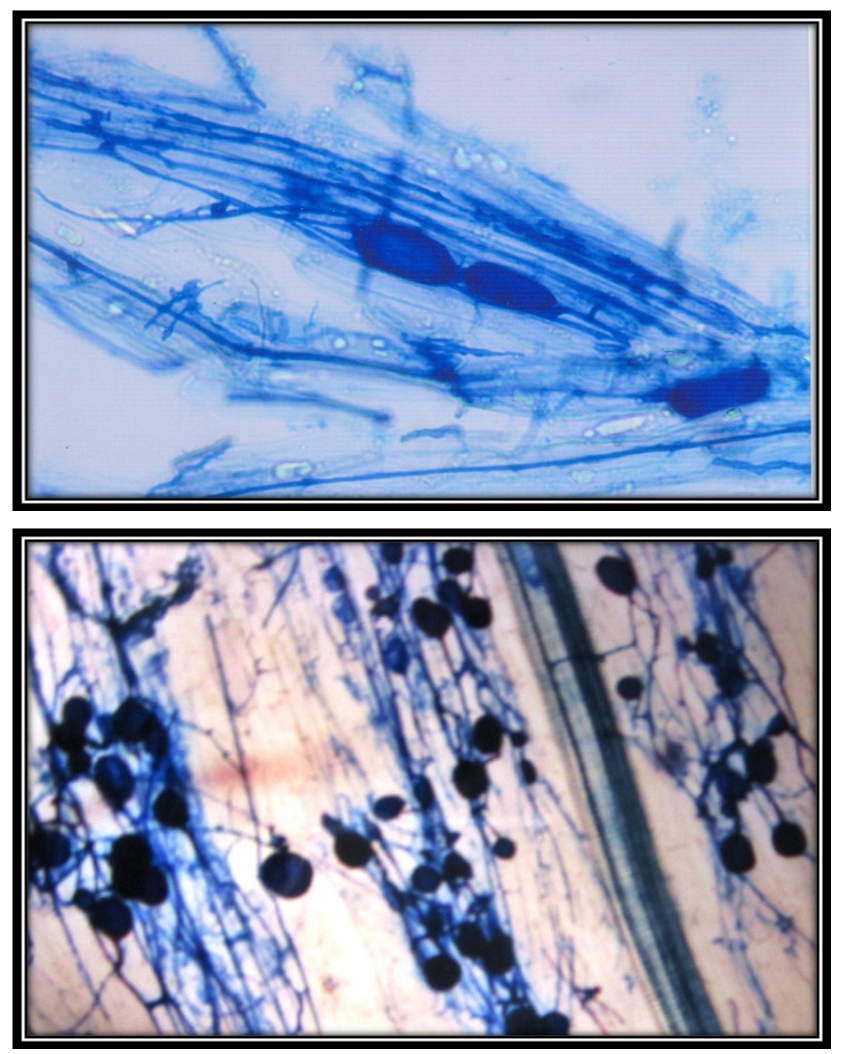

Plate 1- Effect of AM inoculum with $80 \%$ colonized root bits on root colonization of Maize

\section{Total root length colonization of Maize by AM fungi}

The results showed that among the four treatments analysed, treatment T4 which received $100 \%$ colonized root bits in AM inoculum had maximum AM fungal total root length colonization (82 per cent) followed by $T_{3}$ that received $80 \%$ colonized root bits (72 per cent) when vermiculite was used as the substrate material (Table 3). Similarly, significant enhancement in total root length colonization was recorded in the treatment T4 (89 per cent), followed by T3 (80 per cent) when vermiculite $+10 \%$ soil was used as the substrate material. While uninoculated control had no AM fungal colonization. The interaction effect was observed significant. No treatments were on par with each other and all the treatments were statistically significant from each other. 


\section{Enumeration of viable AM spores in the substrates}

Viable spore numbers of AM fungi in substrate was significantly influenced with the range of colonized root bits in the AM inoculum (Figure 1). Among the substrates used, vermiculite $+10 \%$ soil recorded maximum number of viable spores compared to vermiculite at both the days of sampling. Among the treatments, $\mathrm{T}_{4}$ that received $100 \%$ colonized root bits recorded the maximum spore count compared to all the other treatments. No AM spores was observed in control.

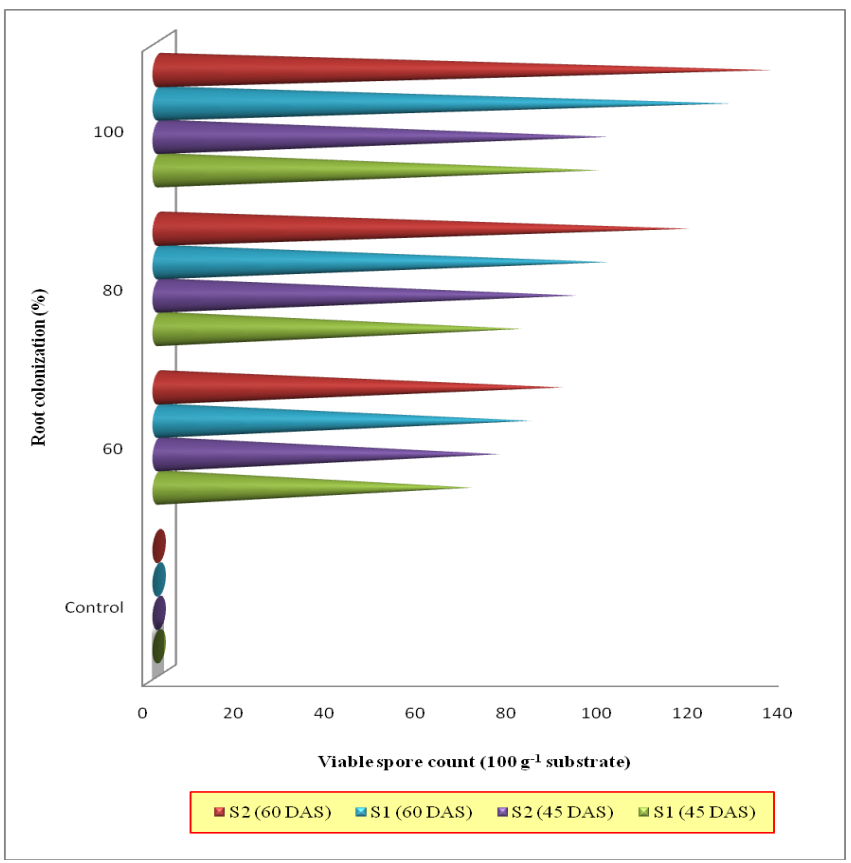

Fig. 1- Effect of $A M$ inoculum with various levels of AM colonization on the viable spore

\section{Discussion}

Infected roots contain internal fungal mycelium as well as external mycelium, vesicles and in some species AMF spores. Before being used as inoculum, roots are often chopped into small pieces. It is well known that the effectiveness of the infected roots as an inoculum source is higher than that of spores (Sieverding, 1991). Hence colonization of AM root bits is also considered as one of the quality parameters that have to be standardized to ensure the quality of the inoculant for effective crop growth response.

A study was conducted to find out the AM colonization to be present in the roots of host plant raised for AM inoculum production to ensure enhanced effectivity using maize as host plant under pot culture conditions up to 60 days. Two different types of substrates were tried. One was vermiculite and the other was vermiculite amended with $10 \%$ soil.

The critical observation of the results depicts that $80 \%$ and $100 \%$ colonized root bits in the inoculum exhibited higher crop growth response at 60 days when vermiculite was amended with $10 \%$ soil. Treatments that received 100 and $80 \%$ colonized root bits recorded an increase of 76.4 and 64.7 per cent root volume and 170.0 and 163.3 per cent total dry weight of maize at 60 days in amended vermiculite. Earlier studies in colonization levels of $A M$ in the fungal inoculum showed the same trend for medicinal plants wherein $90 \%$ colonized root bits were used as $\mathrm{AM}$ inoculum source which exhibited 100 per cent root colonization (Poulton et al., 2002).

Maximum root colonization of 98 per cent was observed in the treatment that received $100 \%$ colonized root bits followed by 90 per cent in the treatment that received $80 \%$ colonized root bits at 60 days in vermiculite $+10 \%$ soil. Similar trend was observed with regard to the total root length colonization and viable $A M$ spore density also.

The results are in line with the findings of Saif, 1984 who reported that 90 per cent colonized root bits is suitable root colonization required for $\mathrm{AM}$ inoculum production in large scales commercially. Neumann and George (2005) reported that higher root colonization results by the addition of mother inoculum containing higher per cent of colonized root bits ranging from 80 to $100 \%$ which will result in increased plant root volume, nutrient uptake and plant growth.

This may be substantiated that, the infected root bits are the major source of active and living propagule of the fungus. The infected root bits contain living hyphae, vesicles, arbuscules and internal spores. When it is applied as inoculum source, further proliferation of AM structures occurs when host plants are grown in the substrates. Hence the root colonization will be enhanced in the host plants with the inoculation of highly colonized root segments.

\section{Conclusion}

Hence, > $80 \%$ root colonization is recommended as one of the quality standard to ensure the quality of $A M$ inoculum that will result in better colonization in the inoculated plants at field level and bring in accelerated crop growth response. More than 80 per cent colonized root bits will act as an excellent source of mother inoculum for the preparation of standardized AM inoculum in the near future.

\section{References}

[1] Feldmann F. and Schneider C. (2009) Can. J. Bot., 2: 13661380.

[2] Feldmann F., Hutter I. and Schneider C. (2010) Federal research centers for Agriculture and forestry. Mersewery, 11-12.

[3] Douds D.D., Nagahashi G. and Hepperly P.R. (2010) Biores. Tech., 1: 2326-2330.

[4] Phillips J.M. and Hayman D.S. (1970) Trans. Brit. Mycol. Soc., 13: 31-32.

[5] Burdette A.N. (1979) Can. J. Fores. Res., 9:120-122.

[6] McGonigle T.P. and Fitter A.H. (1988) New Phytol., 108: 5965.

[7] Panse V.G. and Shukatme P.V. (1978) Indian council of Agric. Res., New Delhi, 327.

[8] Sieverding E. (1991) Eschborn, Germany, 12-28.

[9] Poulton J.L., Bryla D., Koide R.T. and Stephensen A.G. (2002) New Phytol., 15: 255-264.

[10]Neumann E. and George E. (2005) Mycorrhiza, 15: 533-537. 
Table 1- Effect of AM inoculum with various levels of AM colonization on root biomass and dry weight of Maize

\begin{tabular}{|c|c|c|c|c|c|c|c|c|c|c|c|c|}
\hline \multirow{3}{*}{ Treatments } & \multicolumn{6}{|c|}{ Root volume (cm plant $\left.^{-1}\right)$} & \multicolumn{6}{|c|}{ Total dry weight (g plant $\left.{ }^{-1}\right)$} \\
\hline & \multicolumn{2}{|c|}{45 DAS } & Mean & \multicolumn{2}{|c|}{60 DAS } & \multirow{2}{*}{ Mean } & \multicolumn{2}{|c|}{45 DAS } & \multirow{2}{*}{ Mean } & \multicolumn{2}{|c|}{60 DAS } & \multirow{2}{*}{ Mean } \\
\hline & $\mathbf{s}_{1}$ & $\mathrm{~S}_{2}$ & Mean & $s_{1}$ & $S_{2}$ & & $\mathbf{s}_{1}$ & $S_{2}$ & & $s_{1}$ & $S_{2}$ & \\
\hline $\mathrm{T}_{1}$ - Uninoculated control & 1.0 & 1.2 & 1.1 & 1.7 & 2.1 & 1.9 & 2.6 & 2.8 & 2.7 & 3.0 & 3.3 & 3.1 \\
\hline $\mathrm{T}_{2}-60 \%$ colonized root bits & $\begin{array}{c}2.2 \\
(120.0)\end{array}$ & $\begin{array}{c}2.3 \\
(130.0)\end{array}$ & 2.3 & $\begin{array}{c}2.5 \\
(47.0)\end{array}$ & $\begin{array}{c}2.6 \\
(52.9)\end{array}$ & 2.5 & $\begin{array}{c}5.0 \\
(92.3)\end{array}$ & $\begin{array}{c}5.8 \\
(123.0)\end{array}$ & 5.4 & $\begin{array}{c}5.9 \\
(96.6)\end{array}$ & $\begin{array}{c}6.4 \\
(113.3)\end{array}$ & 6.1 \\
\hline $\mathrm{T}_{3}-80 \%$ colonized root & $\begin{array}{c}2.3 \\
(130.0)\end{array}$ & $\begin{array}{c}2.4 \\
(140.0)\end{array}$ & 2.4 & $\begin{array}{c}2.6 \\
(52.9)\end{array}$ & $\begin{array}{c}2.8 \\
(64.7)\end{array}$ & 2.7 & $\begin{array}{c}6.8 \\
(161.5)\end{array}$ & $\begin{array}{c}7.1 \\
(173.0)\end{array}$ & 6.9 & $\begin{array}{c}7.7 \\
(156.6)\end{array}$ & $\begin{array}{c}7.9 \\
(163.3)\end{array}$ & 7.8 \\
\hline $\mathrm{T}_{4}-100 \%$ colonized root bits & $\begin{array}{c}2.4 \\
(140.0) \\
\end{array}$ & $\begin{array}{c}2.6 \\
(160.0) \\
\end{array}$ & 2.5 & $\begin{array}{c}2.8 \\
(64.7) \\
\end{array}$ & $\begin{array}{c}3.0 \\
(76.4) \\
\end{array}$ & 2.9 & $\begin{array}{c}6.8 \\
(161.5) \\
\end{array}$ & $\begin{array}{c}7.2 \\
(176.9) \\
\end{array}$ & 7.0 & $\begin{array}{c}8.0 \\
(166.6) \\
\end{array}$ & $\begin{array}{c}8.1 \\
(170.0) \\
\end{array}$ & 8.0 \\
\hline & & & SEd & & & $<0.05)$ & & SEd & & & $<0.05)$ & \\
\hline Treatments & & & 0.07 & & & & & 0.06 & & & & \\
\hline Days & & & 0.05 & & & & & 0.04 & & & & \\
\hline Substrates & & & 0.05 & & & & & 0.04 & & & & \\
\hline Treatments $x$ Days & & & 0.11 & & & & & 0.09 & & & & \\
\hline Days $x$ Substrates & & & 0.07 & & Ns & & & 0.06 & & $\mathrm{~N}$ & & \\
\hline Treatments $\times$ Substrates & & & 0.11 & & NS & & & 0.09 & & & & \\
\hline Treatments $\times$ Days $\times$ Substrates & & & 0.15 & & NS & & & 0.12 & & $\mathrm{~N}$ & & \\
\hline
\end{tabular}

DAS - Days after sowing. S1 - Sterile vermiculite alone, S2 - Sterile vermiculite $+10 \%$ soil, Values represent mean of five replications, Values in paranthesis indicate per cent increase over control, ${ }^{* *}$ - significant at $p<0.01$, NS - not significant.

Table 2- Effect of AM inoculum with various levels of AM colonization on root colonization of Maize

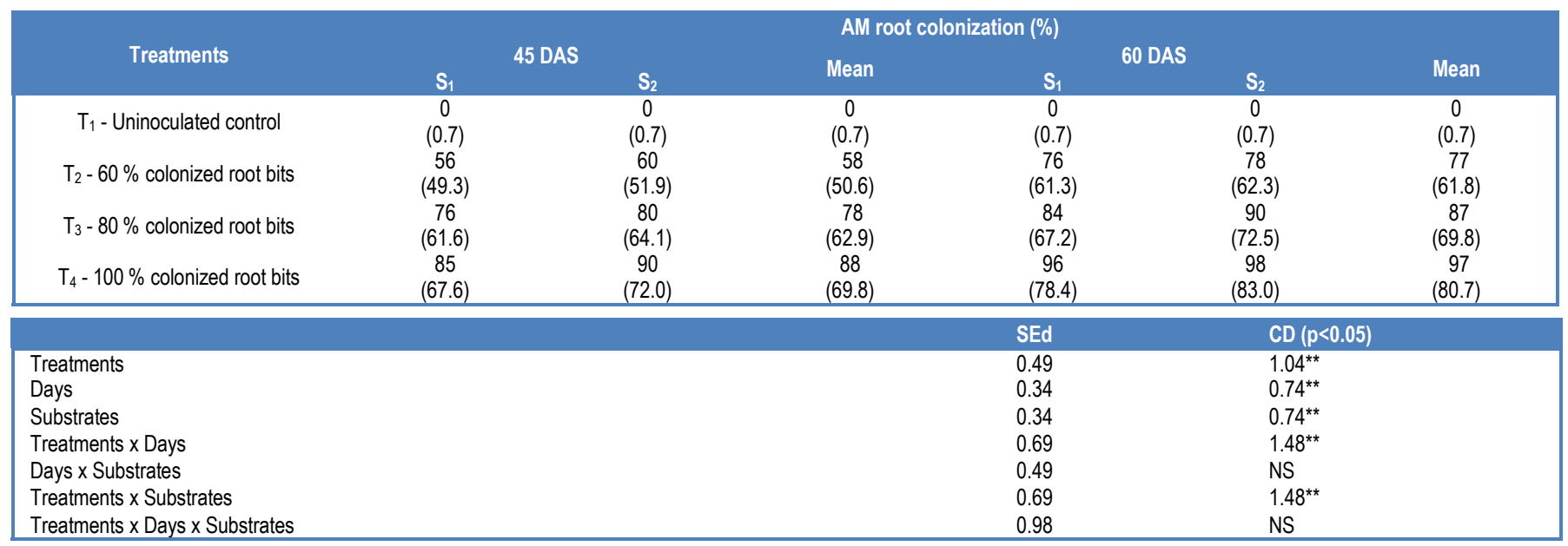

DAS - Days after sowing, S1 - Sterile vermiculite alone, S2 - Sterile vermiculite $+10 \%$ soil, Values represent mean of five replications, Values in paranthesis indicate the per cent transformed values, ${ }^{* *}$ - significant at $p<0.01$, NS - not significant.

Table 3- Effect of AM inoculum with various levels of AM colonization on the total root length colonization of Maize at 60 days after sowing

\begin{tabular}{|c|c|c|c|c|c|c|c|c|c|c|c|}
\hline \multirow{3}{*}{ Treatments } & \multicolumn{10}{|c|}{ Total root length colonization of Maize (\%) } & \multirow{3}{*}{ Mean } \\
\hline & \multicolumn{2}{|c|}{ vc } & \multicolumn{2}{|c|}{ AC } & \multicolumn{2}{|c|}{ CC } & \multicolumn{2}{|c|}{ HC } & \multicolumn{2}{|c|}{ TRLC } & \\
\hline & $\mathbf{s}_{1}$ & $\mathrm{~S}_{2}$ & $\mathbf{S}_{1}$ & $\mathbf{S}_{2}$ & $s_{1}$ & $S_{2}$ & $s_{1}$ & $S_{2}$ & $s_{1}$ & $\mathrm{~S}_{2}$ & \\
\hline $\mathrm{T}_{1}$ - Uninoculated control & 0 & 0 & 0 & 0 & 0 & 0 & 0 & 0 & $\begin{array}{c}0 \\
(1.0)\end{array}$ & $\begin{array}{c}0 \\
(1.0)\end{array}$ & $\begin{array}{c}0 \\
(1.0)\end{array}$ \\
\hline $\mathrm{T}_{2}-60 \%$ colonized root bits & 8 & 12 & 5 & 9 & 3 & 6 & 33 & 41 & $\begin{array}{c}49 \\
(45.2)\end{array}$ & $\begin{array}{c}68 \\
(55.8)\end{array}$ & $\begin{array}{c}59 \\
(50.5)\end{array}$ \\
\hline $\mathrm{T}_{3}-80 \%$ colonized root bits & 13 & 16 & 9 & 13 & 8 & 9 & 42 & 42 & $\begin{array}{c}72 \\
(58.3)\end{array}$ & $\begin{array}{l}80 \\
(64.1)\end{array}$ & $\begin{array}{c}76 \\
(61.2)\end{array}$ \\
\hline $\mathrm{T}_{4}-100 \%$ colonized root bits & 15 & 17 & 12 & 16 & 7 & 9 & 48 & 47 & $\begin{array}{c}82 \\
(65.2)\end{array}$ & $\begin{array}{c}89 \\
(71.0)\end{array}$ & $\begin{array}{c}86 \\
(68.1)\end{array}$ \\
\hline & & & & SEd & & & & & & & \\
\hline Treatments & & & & 0.47 & & & & & & & \\
\hline Substrates & & & & 0.33 & & & & & & & \\
\hline Treatments $\mathrm{x}$ Substrates & & & & 0.67 & & & & & & & \\
\hline
\end{tabular}

S1 - Sterile vermiculite alone, S2 - Sterile vermiculite + $10 \%$ soil, VC- Vesicular colonization, AC - Arbuscular colonization, CC - Coil colonization, HC - Hyphal colonization, TRLC - Total root length colonization, Values represent mean of five replications, Values in paranthesis indicate per cent transformed values, ${ }^{* *}$ - significant at $p<0.01$. 